\title{
Subcutaneous Cysticercosis - A Case Report
}

\author{
Dr. DN Goyal, Dr. Indira Priyadarshini, Dr. Venkateswara Rao Katta, \\ Dr. V. Ashok Kumar
}

\section{Introduction}

Cysticercosis is one of the most common parasitic infestations in humans. Neurocysticercosis is the commonest parasitosis of the central nervous system. It may present as intramuscular or subcutaneous nodules the later being rare. Clinically it may be mistaken as lipoma or neurofibroma. Even on high resolution ultrasound it may be misdiagnosed if cyst with scolex is not made out.On histopathological examination of the cut sections cysticercous larvae with surrounding inflammation are seen.

\section{Case Report}

A 42 year old female patient had presented with a painless swelling on the abdominal wall with no other relevant history. On local examination there was a solitary firm swelling of $3 \times 2 \mathrm{~cm} 1 \mathrm{~cm}$ below the right coastal margin $4 \mathrm{~cm}$ from the midline, in subcutaneous plane. The mass was clinically diagnosed as lipoma. Routine investigations were within normal limits. On ultrasound the features were suggestive of lipoma. The mass was excised under local anaesthesia and the nodular mass was sent for histopathological exam showed multiple granulomas and the cysticercosae surrounded by eosinophilic infiltrate.

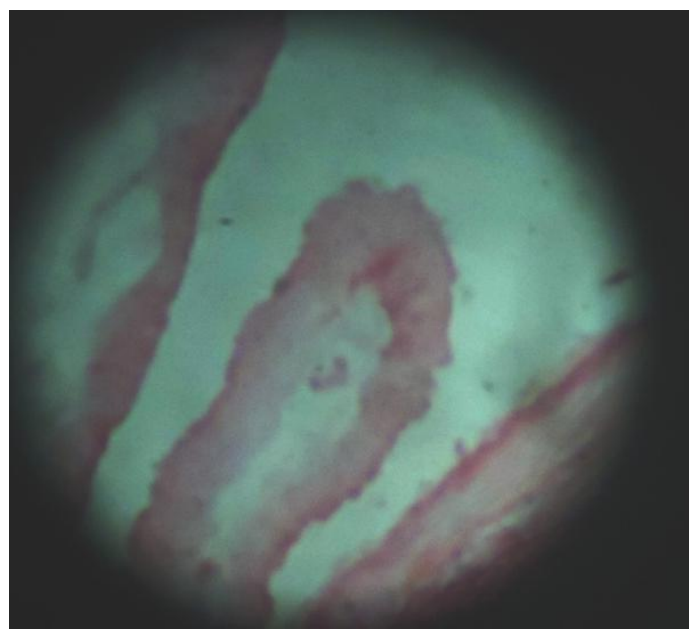

Fig. 1: corrugated chitinous wall of cysticercous cellulosae

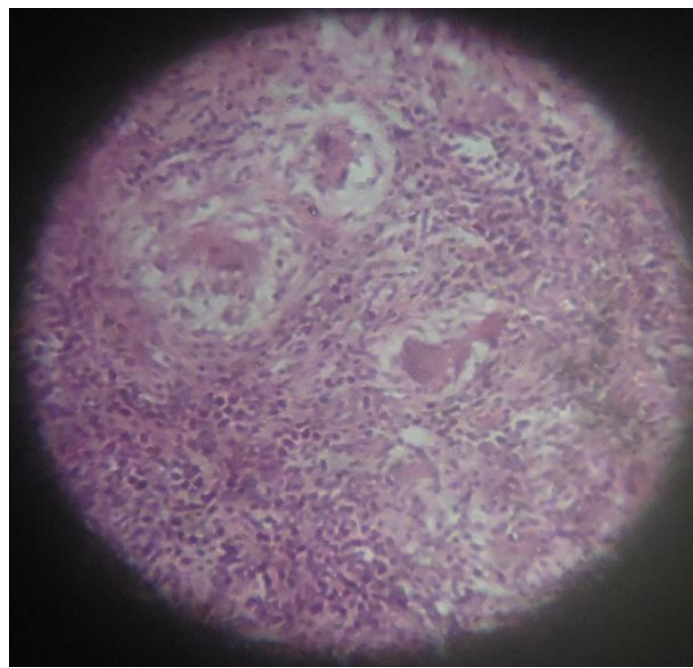

Fig. 2: Granulomas with giant cells 


\section{Discussion}

Cysticercosis is a systemic parasitic infestation caused by Taenia solium. The mode of transmission is faeco-oral by consumption of raw or undercooked beef or pork, water or vegetables contaminated with Taenia eggs. Tape worm eggs (ova) hatch and embryos (oncospheres) penetrate the intestinal wall and reach the blood stream from where they disseminate to different tissues.These oncosphere develop into cysticerci in any organ but are common in brain, subcutaneous cysts are in the form of firm, mobile nodules, occurring mainly on the trunk and extremities. Tense nodules are $1-2 \mathrm{~cm}$ in size, they are deep seated in the subcutaneous tissue, painless to mildly tender with usually normal overlying skin. The differential diagnosis for subcutaneous Cysticercosis includes: Lipoma, neurofibroma, epidermoid cyst, sarcoidosis, scrofula, ganglion cyst, metaplastic carcinoma and lymphadenopathy. Definitive diagnosis is made on histology which reveals tegument of parasite appearing as rounded wavy folds and scolex with hooklets with hyaline membrane surrounding it .The inflammatory reaction to the cyst consists predominantly of eosinophils along with polymorphs, epitheloid cells and giant cells. Radiological studies (USG, CT, MRI) are mandatory to rule out central nervous system involvement. CT scan and MRI are useful in demonstrating the location, size and number of cysts. Surgical excision is the treatment for uncomplicated subcutaneous nodules, however for symptomat ic neurocysticercosis, antiparasitic therapy in combination with corticosteroids and anticonvulsants should be given to reduce the inflammation surrounding the cyst and lower the risk.

\section{Conclusion}

Cysticercosis though common in central nervous system, it can also be seen in the rare sites like the eye, skeletal muscles, and subcutaneous tissue, as is in our case. Hence it should also be kept as differential diagnosis even for the swellings at unusual sites such as the subcutaneous tissue in the endemic areas of Taenia solium infection.

\section{References}

[1]. Rakesh T Shedge, Sanjay G Surase, Milind More, Vaishali N Solanke : subcutaneous cystecercosis : Bombay Hospital Journal, Vol. 54, no.2, 2012

[2]. Pawane P.S, Balamurugan M, Pillai R, Pradep Kumar N.S : Diagnosis of Subcutaneous Cysticercosis In Soft Tissue Mass Over Anterior abdominal Wall: Journal Of Evolution Of Medical and Dental Sciences/ Vol 1/ issue 6/ Dec 2012

[3]. Amit Mittal, Sanjeev Gupta, Sunita Gupta, Vinod Mehta: Subcutaneous and Intramuscular Cysticercosis-High Resolution Sonography: Indian J dermatol Venerol Leprol/ Sep-Oct 2009/ Vol 75/ Issue 5

[4]. Sunita Bamanikar, Tejaswini Malhotra, Parveen Kaur: Soft Tissue Cysticercosis: International Journal of Basic and Applied Medical Sciences ISSN:2277-2103

[5]. S. Gole, G. Gole, V. Satyanarayana, A Deshpande, S.Tati: Cysticercosis at Rare Sites: http://ispub.com/IJPD/5/1/14 340 